\title{
Prolapso vaginal e uterino em ovelhas ${ }^{1}$
}

\author{
Maíra Bianchi R. Alves², Fernando J. Benesi² ${ }^{2}$ Lilian Gregory ${ }^{2}$, Alice M.M.P. \\ Della Libera $^{2}$, Maria Cláudia A. Sucupira ${ }^{2}$, Fábio C. Pogliani ${ }^{2}$ e Viviani Gomes ${ }^{2 *}$
}

\begin{abstract}
Bianchi-Alves M., Benesi F.J., Gregory L., Della Libera A.M.M.P., Sucupira M.C.A, Pogliani F.C. \& Gomes V. 2013. [Uterine and vaginal prolapse in ewes.] Prolapso vaginal e uterino em ovelhas. Pesquisa Veterinária Brasileira 33(2):171-176. Serviço de Clínica de Bovinos e Pequenos Ruminantes, Hospital Veterinário, Departamento de Clínica Médica, Faculdade de Medicina Veterinária e Zootecnia, Universidade de São Paulo, Av. Orlando Marques de Paiva 87, São Paulo, SP 05508-270, Brazil. E-mail: viviani.gomes@usp.br

This study aimed to conduct a retrospective study on vaginal and uterine prolapse in sheep seen at the Clinic and Surgery on Cattle and Small Ruminants (CBPR) at University of São Paulo, from 2000 to 2010. During this period, 56 sheep were treated with problems of the reproductive system. Of these, 25 ewes had vaginal or uterine prolapse (44.6\%). The total vaginal prolapse was the most frequently $(72 \%)$. The majority of sheep that was affected were 4 years old (64\%); most were mixed breed (44\%) and $40 \%$ were Ile de France. Main clinical signs were increased cardiac and respiratory rates, congested ocular mucosa, sternal or lateral recumbence, apathy and anorexia, suggesting toxemia. The treatment of all cases was the cleaning and disinfection of the prolapsed organ and its reintroduction. The Bühner suture was made in $84 \%$ of the cases. The uterus fixation was made in one case (4\%). Recovered was observed in $80 \%$ of the cases and $20 \%$ of the patients died. Vaginal prolapse corresponded to $60 \%$ of the deaths and uterine prolapse to $40 \%$. The etiology of the prolapses had not been defined, but most cases (56\%) occurred during the postpartum period, probably associated with hypocalcaemia, high serum concentrations of estrogen or uterine hypertonia. Furthermore, a genetic predisposition on affected sheep cannot be discharged.

INDEX TERMS: Vaginal prolapse, uterine prolapse, sheep, treatment, etiology.
\end{abstract}

RESUMO.- 0 presente trabalho objetivou realizar um estudo retrospectivo sobre os prolapsos vaginal e uterino em ovelhas atendidas no Serviço de Clínica de Bovinos e Pequenos Ruminantes (CBPR) da FMVZ/USP no período compreendido entre 2000 a 2010, no qual, foram atendidas 56 ovinos com problemas inerentes ao sistema reprodutivo, dessas, 25 apresentaram prolapso vaginal ou uterino $(44,6 \%)$. 0 prolapso vaginal total foi o de maior frequência (72\%). As ovelhas acometidas, em sua maioria, possuíam idade superior a quatro anos (64\%), eram sem raça definida (44\%) ou da raça Ile de France (40\%). As manifestações clínicas observadas durante a maioria dos atendimentos foram: taquipnéia, taquicardia, mucosas oculares avermelhadas indicando estado de toxemia, decúbito esternal ou lateral, apatia

\footnotetext{
${ }^{1}$ Recebido em 19 de julho de 2012.

Aceito para publicação em 5 de novembro de 2012.

${ }^{2}$ Departamento de Clínica Médica, Universidade de São Paulo (USP), Av. Orlando Marques de Paiva 87, São Paulo, SP 05508-270, Brasil. *Autor para correspondência: viviani.gomes@usp.br.
}

e anorexia. 0 tratamento instituído para todos os casos foi a limpeza, desinfecção e reintrodução do órgão prolapsado. A sutura de Bühner foi feita em $84 \%$ dos casos e a histeropexia em um caso (4\%). A evolução foi satisfatória em $80 \%$ dos casos atendidos, nos demais casos (20\%) observou-se óbito da fêmea acometida. Do total de óbitos, os prolapsos vaginais foram responsáveis por $60 \%$ (3/5) e os prolapsos uterinos por $40 \%(2 / 5)$. A etiologia dos prolapsos não foi definida nos casos atendidos, sendo esses associados com o período pós-parto em sua maioria (56\%), provavelmente associados com quadros de hipocalcemia, altas concentrações séricas de estrógeno e hipertonia uterina. Além disso, a predisposição genética não pode ser descartada.

TERMOS DE INDEXAÇÃO: Prolapso vaginal, prolapso uterino, ovelha, tratamento, etiologia.

\section{INTRODUÇÃO}

As disfunções obstétricas causam grandes perdas econômicas na ovinocultura (Majeed \& Taha 1995). Distocias, 
prolapsos uterinos, retenção dos anexos fetais e metrite puerperal são as disfunções obstétricas mais frequentes em ovelhas no Iraque. A ocorrência de prolapsos uterinos observada nestas ovelhas foi de 14,3\% (Majeed \& Taha 1995). No Reino Unido, em estudos realizados entre 1970 e 1990, a incidência de prolapso vaginal em ovelhas variou de 0 a 15\% em relação às demais disfunções obstétricas e a reincidência desses variou de 40 a 55\% (Stubbings 1971, Scott \& Gessert 2005). Levantamento realizado com ovelhas no Agreste e Sertão de Pernambuco, região Nordeste do Brasil, mostrou que dos 60 casos de distocia atendidos, quatro apresentavam dilatação cervical insuficiente e prolapso vaginal correspondendo a $6,67 \%$ do total de distocias atendidas (Câmara et al. 2009).

Os prolapsos pélvicos possuem grande importância econômica, pois podem ocasionar abortamento, baixa eficiência reprodutiva, perda de matriz de alto valor zootécnico, aumento das taxas de mortalidade perinatal e distocias (Sobiraj 1990, Noakes et al. 2001). A ocorrência de prolapsos está associada com o período do peri-parto (Noakes et al. 2001, Scott 2005, Prestes \& Landim-Alvarenga 2006). Entretanto, há relatos de ocorrência da afecção em fêmeas não gestantes e que não estejam no período puerperal (Noakes et al. 2001, Prestes et al. 2009, Sales et al. 2011). As fêmeas ovinas são mais acometidas que as fêmeas bovinas e caprinas (Sobiraj 1990, Noakes et al. 2001), sendo as caprinas as menos acometidas (Prestes \& Landim-Alvarenga 2006).

Os prolapsos vaginais, classificados em parciais ou totais de acordo com a exposição cervical (Grunert \& Birgel 1984, Noakes et al. 2001), caracterizam-se pelo relaxamento da fixação da vagina na cavidade pélvica, permitindo modificação da posição da parede vaginal com saída e exteriorização da mucosa através da rima vulvar (Prestes \& Landim-Alvarenga 2006). 0 prolapso vaginal total é mais frequente em ovelhas, enquanto o parcial é mais frequente em vacas (Grunert \& Birgel 1984, Noakes et al. 2001). 0 prolapso uterino caracteriza-se pela eversão do útero, invertendo-se e exteriorizando sua mucosa. Este é classificado em parcial (um corno prolapsado), completo (dois cornos prolapsados) e completo e total (dois cornos e cérvix prolapsados) de acordo com a exposição de um ou dois cornos uterinos e cérvix (Grunert \& Birgel 1984). Este tipo de prolapso é comum em vacas e ovelhas (Jackson 2005). 0 prolapso vaginal pode evoluir para o prolapso uterino, devido ao ressecamento da mucosa vaginal prolapsada, que a torna irritada e inflamada, contribuindo para maior exposição do órgão (Drost 2007).

Ao exame físico, a ovelha com prolapso vaginal ou uterino pode apresentar anorexia, perda de peso, baixo escore de condição corporal, taquisfigmia e fraqueza, causada por exaustão e esforço constante. Dependendo do tempo de duração do prolapso e do grau de lesões na mucosa prolapsada, esses animais podem apresentar sinais de endotoxemia e septicemia pelo estado necrótico e contaminado da mucosa exposta. Nesses casos, o animal fica dispneico, a respiração torna-se abdominal e as mucosas oculares ficam avermelhadas com os vasos episclerais ingurgitados. Há grandes chances de óbito, devendo o veterinário agir rapidamente. 0 grau de vaginite, vulvite, cervicite e comprometimento uterino variam conforme a duração da afecção e dependem da ação dos agentes mecânicos, térmicos ou infecciosos sobre as mucosas prolapsadas. Devido à irritação e à congestão venosa há ocorrência de edema em vagina, cérvix e útero. Em animais gestantes, pode haver liberação parcial ou total do tampão mucoso podendo haver então abortamento ou parto prematuro (Prestes \& Landim-Alvarenga 2006).

As causas determinantes para a ocorrência dos prolapsos vaginais e uterinos nos ovinos ainda não estão bem esclarecidas, entretanto sabe-se que há fatores predisponentes que irão determinar a ocorrência ou não do prolapso. Fatores predisponentes para a ocorrência de prolapsos vaginais e uterinos em ovelhas incluem: disfunções hormonais (Sobiraj et al. 1986, Sobiraj 1990, Noakes et al. 2001); hipocalcemia (Silva et al. 1984, Sobiraj et al. 1986); aumento da pressão intra-abdominal (Noakes et al. 2001) causada por gestações gemelares (Majeed \& Taha 1995, Noakes et al. 2001, Scott 2005, Prestes \& Landim-Alvarenga 2006); obesidade; hidropsia dos envoltórios fetais (Prestes \& Landim-Alvarenga 2006) e/ou timpanismo (Prestes \& Landim-Alvarenga 2006); uso de estrógenos como anabolizantes e fornecimento de alimentos com alto teor de estrógeno como plantas fitoestrogênicas e alimentos mofados (Sobiraj et al. 1986, Sobiraj 1990, Prestes \& Landim-Alvarenga 2006); predisposição hereditária (Prestes \& Landim-Alvarenga 2006); defeitos anatômicos (Prestes et al. 2009); relaxamento exagerado do sistema de fixação da vagina em fêmeas idosas e/ou multíparas (Prestes \& Landim-Alvarenga 2006); e inflamações na região da vulva e do reto (Noakes et al. 2001, Prestes \& Landim-Alvarenga 2006).

0 prolapso vaginal pode ocorrer pelo aumento da concentração sérica de estrógeno (Sobiraj 1990, Prestes \& Landim-Alvarenga 2006). Estudo recente de Ennen et al. (2011) com ovelhas que apresentaram prolapso vaginal no período pré-parto, mostrou que havia aumento na concentração sérica de estrógeno dessas ovelhas em relação a outras ovelhas no mesmo período gestacional e que não apresentaram prolapso vaginal. Entretanto, este aumento não teve significância estatística.

Segundo Stubbings et al. (1971) a diminuição nos teores de cálcio está associada com os prolapsos vaginais em ovelhas. A indução experimental de hipocalcemia em ovelhas em diferentes fases do parto mostrou que baixas concentrações de cálcio podem reduzir a atividade uterina no primeiro, no terceiro e no quarto estágio do parto, no qual, considera o primeiro estágio correspondente ao início das atividades uterinas, o segundo ao início das contrações abdominais, o terceiro ao rompimento das bolsas fetais e o quarto ao período pós-parto (Silva et. al. 1984). Portanto, a hipocalcemia na segunda fase do parto, diferentemente da ocorrência dela nos outros estágios, não seria um fator predisponente importante para a ocorrência de prolapsos uterinos nas ovelhas. Em vacas no período puerperal associa-se a ocorrência de prolapsos uterinos à hipocalcemia (Smith 2006). Entretanto, o diagnóstico diferencial deve ser feito levando-se em consideração a distocia associada à extração forçada do produto, que também podem resultar em prolapso (Smith 2006). 
Em vacas da raça Brahman e Nelore tem aumentado a ocorrência de prolapsos vaginais não relacionados com o período gestacional (Prestes et al. 2009, Sales et al. 2011). A ocorrência de prolapsos vaginais em fêmeas que não estejam gestantes ou no período puerperal só foi descrita em cadelas, podendo ser considerada uma nova modalidade de prolapso em bovinos. Relata-se a ocorrência em fêmeas nulíparas, primíparas e multíparas (Prestes et al. 2009). Observa-se aumento da ocorrência dessa afecção em fêmeas reprodutoras de genética comprovada que estejam em período de colheita frequente de oócitos por punção ovariana (Prestes et al. 2009; Sales et al. 2011). Para a colheita de oócitos é feita a anestesia epidural, esta se associa à formação de neuroma na cauda equina que pode levar a ocorrência de prolapsos (Sales et al. 2011). Não há, até o momento, relatos da ocorrência de prolapsos relacionadas a este fator predisponente em ovelhas.

Segundo Bortolini et al. (2011) a expressão alterada da proteína óssea morfogenética 1 em tecido vaginal relacionou-se com a ocorrência de prolapso pélvico em mulheres. A disfunção dessa proteína, portanto, pode resultar em deficiência do tecido conjuntivo vaginal facilitando a ocorrência desta enfermidade (Bortolini et al. 2011). Em outro estudo, conduzido em humanos, foi visto que a expressão da elastina em tecido vaginal de mulheres após a menopausa era aumentada. Este aumento correlacionou diretamente com o desenvolvimento de prolapsos pélvicos nessas mulheres (Moon et al. 2011). Em humanos se estuda ainda a possível correlação da quantidade de colágeno em tecido vaginal com a ocorrência de prolapsos pélvicos, tendo-se demonstrado correlação positiva em alguns estudos (Jackson et al. 1996). Em ovelhas foi demonstrado que esta relação parece não existir (Ayen \& Noakes 1998).

O tratamento de escolha para os prolapsos vaginais e uterinos em ovelhas dependerá da causa, gravidade e tempo de gestação (Prestes \& Landim-Alvarenga 2006, Huaixan et al. 2011, Sales et al. 2011). 0 prolapso deverá ser tratado juntamente com as afecções primárias a ele, tais como hidropsia e timpanismo (Prestes \& Landim-Alvarenga 2006). Deve ser realizada a desinfecção, limpeza da mucosa vaginal e/ou uterina e avaliação dessa mucosa quanto a lacerações, rupturas e áreas de necrose (Prestes \& Landim-Alvarenga 2006, Huaixan et al. 2011). Com base na avaliação da mucosa prolapsada, da etiologia e da fase da gestação, pode ser feita a recolocação da área prolapsada e a reparação ou até mesmo a histerectomia (Prestes \& Landim-Alvarenga 2006, Prestes et al. 2009, Sales et al. 2011).

Em algumas situações quando é realizada a reintrodução da área prolapsada, pode ser necessária a intervenção cirúrgica para assegurar que não tenha reincidência do prolapso, entretanto, nesses casos, deve-se atentar ao período pré-parto (Prestes \& Landim-Alvarenga 2006, Prestes et al. 2009). A aplicação de anestesia epidural utilizando-se lidocaína a $2 \%$ ou esta associada à xilazina é fundamental para o sucesso na recolocação do prolapso (Scott \& Gessert 1997, Prestes \& Landim-Alvarenga 2006). A anestesia epidural pode ou não ser acompanhada de intervenção cirúrgica. A sutura de Bühner é a técnica cirúrgica mais utilizada em ruminantes devido a sua praticidade e eficiência
(Prestes \& Landim-Alvarenga 2006). A vaginopexia, pela técnica de Minchev, foi realizada com sucesso de 100\% em duas vacas com prolapso vaginal não associado à gestação, ocasionado provavelmente por neuroma na cauda equina, decorrente de seguidas anestesias epidurais (Sales et al. 2011).

Nos casos em que a mucosa vaginal e/ou uterina está comprometida, edemaciada, friável, com áreas de necrose e lacerada, a indicação é a reparação ou a amputação do órgão (Prestes \& Landim-Alvarenga 2006, Huaixan et al. 2011). A histerectomia por via vaginal utilizando garrote elástico foi descrita por Huaixan et al. (2011) com sucesso em todos os animais submetidos ao procedimento e atendidos no Hospital Veterinário de Grandes Animais da Universidade de Brasília, Brasil (Huaixan et al. 2011). Em mulheres, estudos têm sido feitos para realizar a reparação e a colocação de enxertos ou biomateriais que possibilitem a manutenção do órgão para minimização dos prejuízos reprodutivos (Cervigni et al. 2011, Huang et al. 2012, Reid 2011, Sokol et al. 2012, Wang et al. 2011). Entre os pesquisadores ainda há divergência sobre a utilização dos biomateriais, pois alguns observaram altos índices de recidiva dos prolapsos quando da utilização destes enquanto outros observaram taxas altas de sucesso com a técnica (Cervigni et al. 2011, Huang et al. 2012, Sokol et al. 2012). Além disso, ainda não está comprovado o retorno à função reprodutiva quando os biomateriais são utilizados (Wang et al., 2011).

Apesar da alta freqüência de prolapsos uterinos em ovelhas, em relação às vacas e cabras, poucos estudos apresentam condutas particulares para a espécie. Portanto, este estudo retrospectivo tem por objetivo apresentar os fatores de risco, as manifestações clínicas, a terapêutica e o prognóstico dos casos de prolapso uterino em ovelhas atendidas no Serviço de Clínica de Bovinos e Pequenos Ruminantes da FMVZ/USP, do período de 2000 a 2010.

\section{MATERIAL E MÉTODOS}

Para a realização do presente trabalho foram analisadas as fichas clínicas de 56 animais da espécie ovina, machos e fêmeas, com afecções reprodutivas, atendidos na CBPR da FMVZ/USP, provenientes de cidades do Estado de São Paulo e em casos pontuais de animais vindos do Estado do Paraná e Minas Gerais. 0 período compreendido de atendimento foi entre os anos 2000 a 2010 . 0 levantamento dos dados considerou raça, idade, período gestacional, estação do ano, exame clínico geral, exame específico do aparelho genital, tratamento e evolução clínica do prolapso vaginal e uterino de ovelhas.

O exame clínico geral consistiu na avaliação das funções vitais (frequência cardíaca, frequência respiratória, movimentação ruminal e temperatura corpórea), mucosas, linfonodos e hidratação. 0 exame específico do aparelho genital foi realizado conforme os procedimentos descritos por Dirksen \& Grunder, 1993.

\section{RESULTADOS}

No período compreendido entre 2000 a 2010 foram atendidos 221 quadros clínicos referentes às afecções reprodutivas em bovinos, ovinos e caprinos, estes casos corresponderam a 5,2\% do total de animais doentes atendidos no serviço, destes $86,4 \%$ acometeram fêmeas e $13,6 \%$ machos. 
Dentre os quadros reprodutivos em machos e fêmeas, $24,9 \%$ foram distocias, $17,1 \%$ prolapsos vaginal/uterino, $12 \%$ endometrite e $12 \%$ abortamento. As enfermidades de ocorrências menos expressivas, correspondente a $34 \%$ dos casos reprodutivos, foram cervicites, vaginites, orquites, retenções de anexos fetais e lacerações.

Bovinos machos e fêmeas foram os mais acometidos pelas afecções reprodutivas com $45,3 \%$ de ocorrência, seguidos pelos caprinos com $29,4 \%$ e pelos ovinos com $25,3 \%$. Dentre as afecções reprodutivas em carneiros e ovelhas, o prolapso vaginal e uterino foi a afecção mais frequente e apresentou ocorrência de 44,6\%. Nos bovinos e caprinos, houve baixa ocorrência de prolapso vaginal e uterino, correspondentes a $10 \%$ e $1,5 \%$, respectivamente, dentre as afecções reprodutivas. Os prolapsos vaginal parcial, vaginal total e uterino em ovelhas corresponderam a $8 \%, 72 \%$ e $20 \%$, respectivamente (Quadro 1).

\section{Quadro 1. Características observadas nos quadros clínicos de prolapsos vaginal e uterino em ovelhas} atendidas na CBPR/FMVZ/USP

\begin{tabular}{lc}
\hline \multicolumn{1}{c}{ Características } & Ocorrência \\
\hline Tipo de Prolapso & \\
Prolapso vaginal parcial & $8 \%(2 / 25)$ \\
Prolapso vaginal total & $72 \%(18 / 25)$ \\
$\quad$ Prolapso uterino & $20 \%(5 / 25)$ \\
Idade & \\
Entre um e dois anos & $12 \%(3 / 25)$ \\
Entre dois e quatro anos & $24 \%(6 / 25)$ \\
Mais que quatro anos & $64 \%(16 / 25)$ \\
Raça & \\
Sem raça definida & $44 \%(11 / 25)$ \\
Ile de France & $40 \%(10 / 25)$ \\
Santa Inês & $12 \%(3 / 25)$ \\
Suffolk & $4 \%(1 / 25)$ \\
Estação do ano & \\
Primavera & $48 \%(12 / 25)$ \\
Outono & $28 \%(7 / 25)$ \\
Inverno & $16 \%(4 / 25)$ \\
Verão & $8 \%(2 / 25)$ \\
Período & \\
Pós-parto & \\
Pré-parto & \\
Pré-parto com recidiva pós-parto & $8 \%(14 / 25)$ \\
&
\end{tabular}

Dentre os parâmetros epidemiológicos, pode-se verificar que a maioria das ovelhas com prolapso vaginal ou uterino foram atendidas na primavera (11/25), tinha idade superior a quatro anos $(16 / 25)$ e era sem raça definida $(11 / 25)$ ou da raça Ile de France (10/25) (Quadro 1). Observou-se parto eutócico em $88 \%$ das fêmeas atendidas e a intervenção obstétrica com cesariana ou fetotomia ocorreu em $8 \%$ dos partos das ovelhas com prolapso. A maior ocorrência (56\%) de prolapsos vaginal e uterino foi observada no período pós-parto em relação ao período pré-parto e pré-parto com recidiva (Quadro 1).

No exame clínico geral das fêmeas atendidas, foi possível observar as seguintes manifestações clínicas: taquicardia, taquipnéia, depressão, decúbito, anorexia, hipotermia, desidratação, ausência de movimentos ruminais, dispnéia e mucosas avermelhadas. Presença de secreção vaginal mucopurulenta foi relatada em três das 25 ovelhas após a redução do prolapso. As ovelhas que apresentaram prognóstico de reservado a mau eram as que estavam com baixo escore de condição corporal e com mucosas oculares avermelhadas indicando possível estado de endotoxemia e septicemia.

0 tratamento instituído para todas as ovelhas atendidas com prolapso foi a reintrodução da vagina e/ou útero, sendo feita a limpeza e desinfecção anteriormente ao procedimento. Não foi necessária a realização da histerectomia nos atendimentos realizados. Nos casos em que estavam presentes lacerações, estas foram limpas e o tratamento instituído foi à recolocação do órgão prolapsado e a cicatrização por segunda intenção. Para a reintrodução do prolapso, a anestesia epidural com lidocaína 2\% foi realizada. Em 16\% dos casos foi realizada apenas a reintrodução do órgão. Nos $84 \%$ restantes, foi realizada a reintrodução e a sutura de Bühner que foi retirada aproximadamente após 10 dias da sutura na maioria dos casos. Em um caso foi feita a histeropexia, com sucesso na técnica.

A evolução clínica dos animais atendidos foi satisfatória na maioria dos casos (80\%). O óbito correspondeu a $20 \%$ $(5 / 25)$ dos casos atendidos. Do total de casos de prolapsos uterinos atendidos, $40 \%(2 / 5)$ das ovelhas vieram a óbito. Nos prolapsos vaginais os óbitos representaram $15 \%$ $(3 / 20)$ dos casos.

\section{DISCUSSÃO}

Os dados de atendimento clínico do Serviço de Clínica de Bovinos e Pequenos Ruminantes mostraram que as ovelhas foram as fêmeas mais acometidas por prolapsos. Os prolapsos vaginais e uterinos nestas foram correspondentes a $44,6 \%$ dos casos diagnosticados como enfermidades reprodutivas em ovelhas no estudo, esta ocorrência de prolapsos observada em relação às outras espécies de ruminantes domésticos foi semelhante às observações descritas por Sobiraj (1990), Prestes \& Landim-Alvarenga (2006) e Ennen et al. (2011), que também observaram alta ocorrência de prolapsos vaginal e/ou uterino em ovelhas. Os bovinos assim como os ovinos apresentaram expressiva ocorrência de casos de prolapso, sendo respectivamente $10 \%$ e $44,6 \%$ dos casos reprodutivos de cada espécie, porém as distocias foram às afecções mais frequentes nas vacas. Os caprinos apresentaram poucos casos de prolapsos $(1,5 \%$ dos casos reprodutivos da espécie), condizendo com os dados expostos por Prestes \& Landim-Alvarenga (2006).

Das ovelhas atendidas com prolapsos vaginais e uterinos, os prolapsos vaginais totais foram os mais expressivos ocorrendo em $72 \%(18 / 25)$ das fêmeas acometidas por prolapsos. A maior ocorrência de prolapso vaginal em ovelhas, em relação ao prolapso uterino, também foi observada por Sobiraj (1990). Esse autor constatou que as ovelhas constituem a espécie mais acometida pelo prolapso vaginal. Grunert \& Birgel (1984) e Noakes et al. (2001) afirmaram que o prolapso vaginal total é mais frequente em ovelhas condizendo com os resultados deste trabalho.

Maior número de ovelhas com prolapsos no pós-parto e na primavera foi observado no estudo. Nesta época do ano, a maioria das ovelhas está em fase final de gestação e puerpério relacionando a ocorrência de prolapsos com 
esta fase gestacional. Entretanto, em ovelhas ainda não se sabe exatamente a causa dos prolapsos puerperais. Dessa forma deve-se considerar a relação com partos distócicos e extração forçada do produto (Smith 2006), embora tenha sido constatado no estudo baixa ocorrência de distocias associadas aos casos atendidos.

No período puerperal, o prolapso é associado com hipocalcemia em fêmeas bovinas (Smith 2006). Assim, acredita-se que os casos clínicos atendidos no puerpério possam ser decorrentes de hipocalcemia inaparente, conforme observado por Stubbings et al. (1971) e Silva et al. (1984) que afirmaram que a diminuição nas concentrações séricas de cálcio está associada com a ocorrência de prolapsos em ovelhas (Stubbings et al. 1971), principalmente no primeiro, terceiro e quarto estágio do parto (Silva et al. 1984). Prestes et al. (2009) e Sales et al. (2011) relataram a ocorrência de prolapsos em vacas não relacionados ao período gestacional. Essa nova modalidade de prolapso em ruminantes, não relacionada ao período gestacional, não foi observada nas ovelhas atendidas.

Além do período gestacional e estação do ano, a maioria das ovelhas atendidas com prolapso possuía idade superior a quatro anos. Desta forma, a causa primária da doença pode ter relação com o relaxamento exagerado do sistema de fixação da vagina conforme citado por Prestes \& Landim-Alvarenga (2006), predispondo à doença.

A maioria das ovelhas atendidas na rotina de atendimento clínico do serviço de Clínica de Bovinos e Pequenos Ruminantes é da raça Santa Inês, nativa do Brasil e disseminada no Estado de São Paulo. No entanto, a ocorrência de prolapsos em ovelhas dessa raça foi baixa (12\%). Em contrapartida, observou-se alta ocorrência dessa enfermidade em animais da raça Ile de France (40\%), provavelmente pela sua condição de escore corporal, com grande acúmulo de gordura, que pode provocar aumento da pressão intra-abdominal (Noakes et al. 2001). Além disso, as ovelhas desta raça provinham em sua maioria de uma mesma propriedade, podendo estar relacionada com o manejo, nutrição ou genética.

A predisposição genética dos prolapsos vaginais e uterinos muitas vezes faz com que se eliminem outras causas mais simples, tais como a idade da fêmea e o número de partos. Pesquisas recentes analisaram a histologia vaginal, as concentrações hormonais e os padrões biomoleculares do tecido vaginal para que pudesse ser feita a associação dessas análises com a alta ocorrência de prolapsos vaginais em ovelhas (Ennen et al. 2011). No estudo, observou-se que as ovelhas que haviam tido prolapso vaginal antes do parto apresentavam epitélio vaginal mais espesso que as outras avaliadas em final de gestação ou no momento do parto. Além disso, tinham menor expressão do colágeno I, apresentavam alterações no tecido conjuntivo vaginal e tinham maior concentração sérica de estrógeno, porém sem significância estatística (Ennen et al. 2011).

As observações feitas em tecidos vaginais de mulheres por Bortolini et al. (2011) em relação à expressão da proteína morfogenética 1 cuja disfunção pode resultar em deficiência de tecido conjuntivo vaginal, por Moon et al. (2011) em relação à expressão da elastina cujo aumento está rela- cionado à ocorrência de prolapsos pélvicos em mulheres na menopausa e por Jackson et al. (1996) que observou a ocorrência de prolapso associado diretamente à quantidade de colágeno em tecido vaginal, poderiam ser importantes na determinação da etiologia de prolapsos vaginais em ovelhas.

Segundo Sobiraj (1986), em ovelhas que apresentaram prolapso vaginal antes do parto, houve diminuição da concentração plasmática de cálcio e elevação da concentração de estrógeno e progesterona em relação a ovelhas que não apresentaram o problema. Dessa forma, pode-se associar a ingestão de plantas estrogênicas ou alimentos mofados com a ocorrência de prolapso vaginal, visto que se constatou a doença em ovelhas com concentrações séricas de estrógeno acima do normal no final da gestação (Sobiraj et al. 1986, Prestes \& Landim-Alvarenga 2006). No histórico dos animais atendidos não foi observada relação da ingestão de plantas estrogênicas e alimentos mofados com a ocorrência de prolapsos.

As manifestações clínicas dos casos atendidos foram caraterizadas por taquicardia, taquipnéia, depressão, decúbito, anorexia, hipotermia, desidratação, ausência de movimentos ruminais, dispneia e mucosas avermelhadas e foram semelhantes às descritas para bovinos (Jackson 2005). Os tratamentos instituídos, de acordo com o recomendado para bovinos (Jackson 2005), consistiram basicamente na limpeza, desinfecção e reintrodução do órgão prolapsado seguido ou não pela sutura de Bühner. Estes foram eficientes, podendo ser recomendados para a espécie ovina.

Entretanto, observou-se alta taxa de óbito nas ovelhas acometidas por prolapsos uterinos (40\%). Essa taxa de óbito relativamente maior dos prolapsos uterinos (40\%) frente aos prolapsos vaginais (15\%) pode ser associada à alta contaminação uterina quando comparada à contaminação vaginal levando ao desenvolvimento de choque séptico nessas fêmeas (Prestes \& Landim-Alvarenga 2006). Quando exposta, a superfície da mucosa uterina é maior que a superfície da mucosa vaginal, levando a maior possibilidade de contaminação e quando esta ocorre é mais intensa. A limpeza e desinfecção do útero, por mais que seja realizada de forma correta, pode não ser suficiente para retirar as bactérias presentes e assim essas bactérias uma vez introduzidas podem produzir endotoxinas que levam ao choque. Para evitar este problema, indica-se a lavagem, desinfecção e debridamento de áreas necróticas antes da reintrodução do órgão, evitando assim a produção de endotoxinas. Além disso, a administração de medicação anti-endotóxica e antibiótico sistêmico de amplo espectro é importante para a prevenção do choque.

\section{CONCLUSÕES}

Há alta frequência de prolapsos vaginais e uterinos em ovinos, principalmente no período pós-parto e na estação da primavera.

Fêmeas mais velhas, com mais de quatro anos de idade, e sem raça definida foram as mais acometidas.

0 prolapso vaginal total foi o de maior frequência no estudo. 
A conduta terapêutica adotada mimetizando os procedimentos adotados para fêmeas bovinas foi bem sucedida e pode ser adotada no tratamento de ovelhas com prolapsos vaginal ou uterino.

Agradecimentos.- Aos Docentes de plantão e Médicos-Veterinários residentes do Serviço de Clínica de Bovinos e Pequenos Ruminantes da FMVZ-USP, pelo empenho em examinar, diagnosticar, tratar e registrar os casos atendidos no Hospital Veterinário.

\section{REFERÊNCIAS}

Ayen E. \& Noakes D.E. 1998. Distribution of collagen in the vaginal wall of ewes. Vet. Journal 155(2):213-215.

Bortolini M.A.T., Shynlova O., Drutz H.P., Girão M.J.B.C., Castro R.A., Lye S. \& Alarab M. 2011. Expression of Bone Morphogenetic Protein-1 in vaginal tissue of women with severe pelvic organ prolapse. Am. J. Obstet. Gynecol. 204(6):544-551.

Cervigni M., Natale F., Penna C.L., Saltari M., Padoa A. \& Agostini M. 2011. Collagen-coated polypropylene mesh in vaginal prolapse surgery: an observational study. Eur. J. Obstet. Gynecol. Reprod. Biol. 156(2):223227.

Câmara A.C.L., Afonso J.A.B., Dantas A.C., Guimarães J.A., Costa N.D.A., Souza M.I.D. \& Mendonça C.L.D. 2009. Análise dos fatores relacionados a 60 casos de distocia em ovelhas no Agreste e Sertão de Pernambuco. Ciência Rural 39(8):2458-2463.

Dirksen G. \& Gründer H.D. 1993. Exame Clínico dos Bovinos. Guanabara Koogan, Rio de Janeiro.

Drost M. 2007. Complications during gestation in the cow. Theriogenology 68:487-491.

Ennen S., Kloss S., Scheiner-Bobis G., Failing K. \& Wehrend A. 2011. Histological, hormonal and biomolecular analysis of the pathogenesis of ovine prolapsus vaginae ante partum. Theriogenology 75(2):212-219.

Grunert E. \& Birgel E.H. 1984. Obstetrícia Veterinária, p.82-92. $2^{\text {nd }}$ ed. Sulina, Porto Alegre.

Huaixan L.N., Filho P.C.V., Arruda S.S.B., Bravo M.O., Palermo J.G.C., Godoy R.F., Ximenes F.H.B. \& Borges J.R.J. 2011. Histerectomia com auxílio de garrote elástico como alternativa no tratamento de prolapso uterino. Vet. Zootec. v. 18, n. 4-S.3 [18(4 Supl. 3):497-499.]. (sic)

Huang K.H., Chuang F.C., Fu H.C. \& Kung F.T. 2012. Polypropylene mesh as an alternative option for uterine preservation in pelvic reconstruction in patients with uterine prolapse. J. Obstet. Gynecol. Res. 38(1):97-101.

Jackson P.G.G. 2005. Problemas na gestação; problemas pós-parto em grandes animais, p.29-31; 274-277; 278. In: Coelho C.S. \& Souza V.R.C. (Eds), Obstetrícia Veterinária. $2^{2}$ ed. Roca, São Paulo.

Jackson S., Avery N., Tarlton J., Eckford S., Abrams P. \& Bailey A. 1996.
Changes in metabolism of collagen in genitourinary prolapse. Lancet 347:1658-1661.

Majeed A.F. \& Taha M.B. 1995. Obstetrical disorders and their treatment in Iraqi Awassi ewes. Small Rumin. Res. 17(1):65-69.

Moon Y.J., Choi J.R., Jeon M.J., Kim S.K. \& Bai S.W. 2011. Alteration of elastin metabolism in women with pelvic organ prolapse. J. Urology 185(5):1786-1792.

Noakes D., Parkinson T. \& England G. 2001. Arthur's Veterinary Reproduction and Obstetrics. $8^{\text {th }}$ ed. Elsevier Limits, China.

Prestes N.C. \& Landim-Alvarenga F.C. 2006. Patologias da gestação, p.149154, 182-184. In: Gonçalves R.C. \& Vulcano L.C. (Eds), Obstetrícia Veterinária. Guanabara Koogan, Rio de Janeiro.

Prestes N.C., Moya C.F., Piagentini M. \& Leal S. 2009. Prolapso total ou parcial de vagina em vacas não gestantes: uma nova modalidade de patologia. Revta. Bras. Reprod. Anim. 32(3):182-190.

Reid F. 2011. Uterine prolapse: Preservation or excision? Obstet., Gynecol. Reprod. Med. 21(6):176-179.

Sales J.V.F., Filho P.C.V., Huaixan L.N., Novais E.P.F., Ximenes F.H.B., Borges J.R.J., Godoy R.F. \& Gheller V.A. 2011. Técnica de Minchev em vaca com prolapso de vagina: relato de dois casos. Vet. Zootec. 18(4):516-519.

Scott P.R. 2005. The management and welfare of some common ovine obstetrical problems in the United Kingdom. Vet. Journal 170(1):33-40.

Scott P.R. \& Gessert M.E. 1997. Management of post-partum cervical uterine or rectal prolapses in ewes using caudal epidural xylazine and lignocaine injection. Vet. Journal 153(1):115-116.

Silva J.R., Noakes D.E., Lane H. \& Mymms N. 1984. The effect of experimentally induced hypocalcaemia on uterine activity at parturition in the ewe. Theriogenology 21(4):607-623.

Smith B.P. 2006. Medicina interna de grandes animais, p.1310-1311. Manole, Barueri, SP.

Sobiraj A. 1990. Ante partum vaginal prolapse in sheep-an unsolved problem. Tierärztl. Prax. 18(1):9-12.

Sobiraj A., Busse G., Gips H. \& Bostedt H. 1986. Investigations into the blood plasma profiles progesterone in sheep suffering from vaginal inversion and prolapse ante partum. Brit. Vet. J. 142(3):218-223.

Sokol A.I., Iglesia C.B., Kudish B.I., Gutman R.E., Shveiky D., Bercik R. \& Sokol E.R. 2012. One-year objective and functional outcomes of a randomized clinical trial of vaginal mesh for prolapse. Am. J. Obstet. Gynecol. 206(1):86-94

Stubbings D.P. 1971. Observations on serum calcium levels in ewes in north Lincolnshire in relation to prolapse of the vagina and incomplete cervical dilatation. Vet. Rec. 89:296-300.

Wang C.L., Long C.Y., Juan Y.-S., Liu C.M. \& Hsu C.S. 2011. Impact of total vaginal mesh surgery for pelvic organ prolapse on female sexual function. Int. J. Gynecol. Obstet. 115(2):167-170. 